\title{
Self-Assembly of a Nanoscopic Pt(II) Double Square Cage
}

Sushobhan Ghosh, ${ }^{\mathrm{a}}$ Stuart R. Batten, ${ }^{\mathrm{b}}$ David R. Turner, ${ }^{\mathrm{b}}$ and Partha Sarathi Mukherjee ${ }^{\mathrm{a}}$ * Department of Inorganic and Physical Chemistry, Indian Institute of Science, Bangalore560012, India and School of Chemistry, Monash University, Australia. E-mail: psm@ipc.iisc.ernet.in

\section{Experimental:}

Synthesis of ligand-1: To a $3 \mathrm{mmol} \mathrm{n}-\mathrm{BuLi}$ solution in $20 \mathrm{~mL}$ dry diethylether colled to $-60^{\circ} \mathrm{C}$ was added freshly prepared 4-bromopyridine ( $\left.3 \mathrm{mmol}\right)$ in $20 \mathrm{~mL}$ dry ether with continuous stirring. The light yellow slurry was stirred for another 20 min maintaining the temperature below $-50{ }^{\circ} \mathrm{C} .3 \mathrm{mmol}$ 4-cyanopyridine in $20 \mathrm{~mL}$ dry THF was added slowly to the above cold solution. The mixture was allowed to warm to r.t. and following hydrolysis with $40 \mathrm{~mL}$ water, the ether part was extracted with $6 \% \mathrm{H}_{2} \mathrm{SO}_{4}$ several times. The combined acid parts were heated to remove ether and made basic with dilute $\mathrm{KOH}$ solution. The slurry was extracted with chloroform and dried over magnesium sulfate and evaporated to obtain di-(4-pyridyl) ketone. This ketone was treated with 4-Pyridyllithum in dry ether at $-60^{\circ} \mathrm{C}$ and temperature raised to r.t. the product was diluted with water and extracted with ethylacetate to obtain tris(4-pyridyl)methanol. Tris(4-pyridyl)methanol (1 mmol) and $20 \mathrm{~mL}$ THF were added to a schlenk flask under $\mathrm{N}_{2}$. The reaction was cooled to $-60^{\circ} \mathrm{C}$ in an acetone / liquid nitrogen bath. n-Butyllithium in THF, (1 mmol) was added slowly to the stirred mixture. The reaction was warmed to $-30^{\circ}$ C. 2-Phenylbutyryl chloride (1mmol) was added once at a time and the reaction was then allowed to warm to room temperature. The solvent was removed in vacuo and the residue chromatographed 
on silica gel (ethanol / acetone). The product $\mathbf{1}$ was initially obtained as a light brown paste. Addition of an ethylacetate / hexane mixture (1:1) yielded $\mathbf{1}$ as white powder.

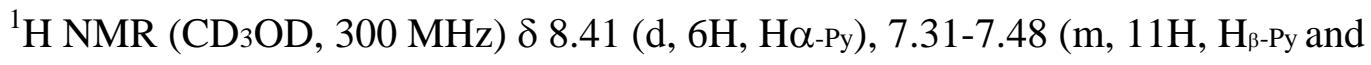
Hphenyl), 3.96 (t, 1H, C(O)-CH), 2.06-1.86 (m, 2H, C(O)-CH(Ph)-CHH) and C(O)$\mathrm{CH}(\mathrm{Ph})-\mathrm{CH} H), 0.78$ (d, 3H, $-\mathrm{CH} 3)$.

\section{Crystallographic Details:}

The structure contains large voids that are occupied by extremely disordered anions and solvent molecules. This reduces the overall precision of the model and limits refinement of the structure to a significant extent. Whilst the connectivity of the $\mathrm{Pt}_{6}$ cage is unambiguous the disorder has a pronounced effect on many of the peripheral ligand groups. Only nine $\mathrm{CF}_{3} \mathrm{SO}_{3}$ anions could be accurately located and the ethyl groups of eight $\mathrm{PEt}_{3}$ ligands could not be reasonably modeled. The chiral group of one of the crystallographically unique ligands could also not be resolved. The SQUEEZE routine of PLATON was therefore applied to the data. A void volume of $6705.3 \AA^{3}$ was calculated to contain 2778 electrons per unit cell. This value represents 1389 electrons per $\mathrm{Pt}_{6}$ cluster. The missing groups (anions, ethyl groups and chiral substituent) calculate to be 491 electrons per cluster leaving 892 electrons worth of solvent disordered in the lattice. Pyridyl rings were constrained with FLAT and SADI restraints where needed. Trifluoromethylsulfonate anions were restrained with DFIX and DANG commands due to apparent disorder and consequently have large anisotropic parameters. One $\mathrm{CF}_{3} \mathrm{SO}_{3}$ anion could not be satisfactorily refined anisotropically and therefore has been refined using an isotropic model. 


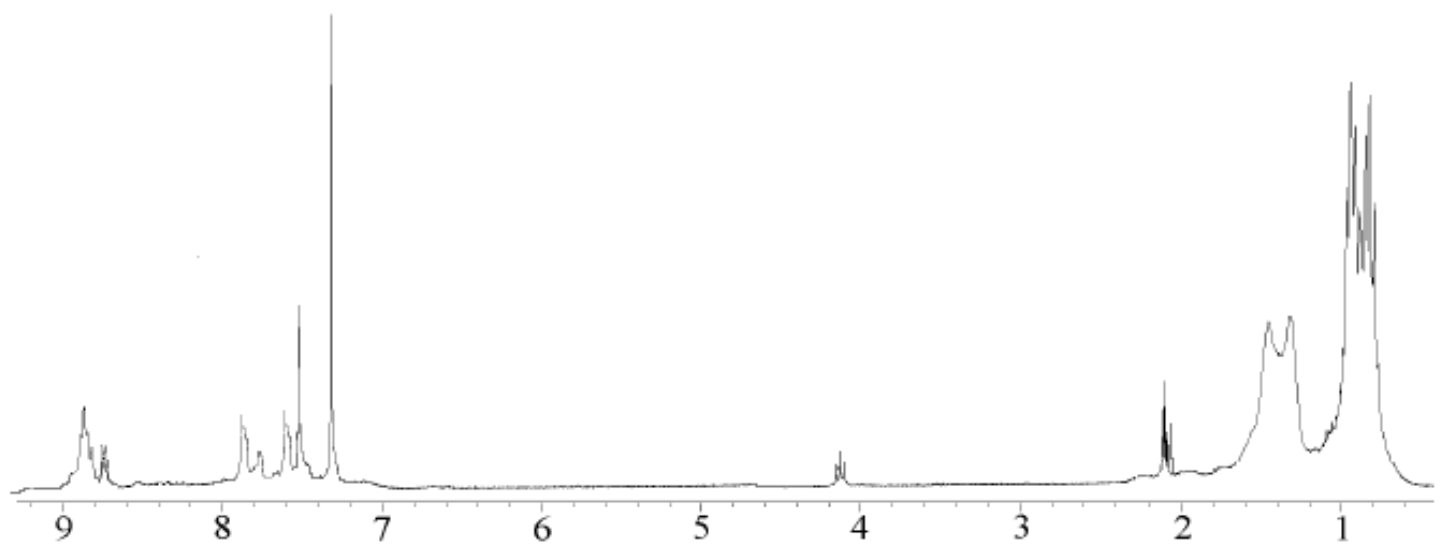

Figure-S1: ${ }^{1} \mathrm{H}$ NMR spectrum of complex 3 in $\mathrm{CDCl}_{3}$.

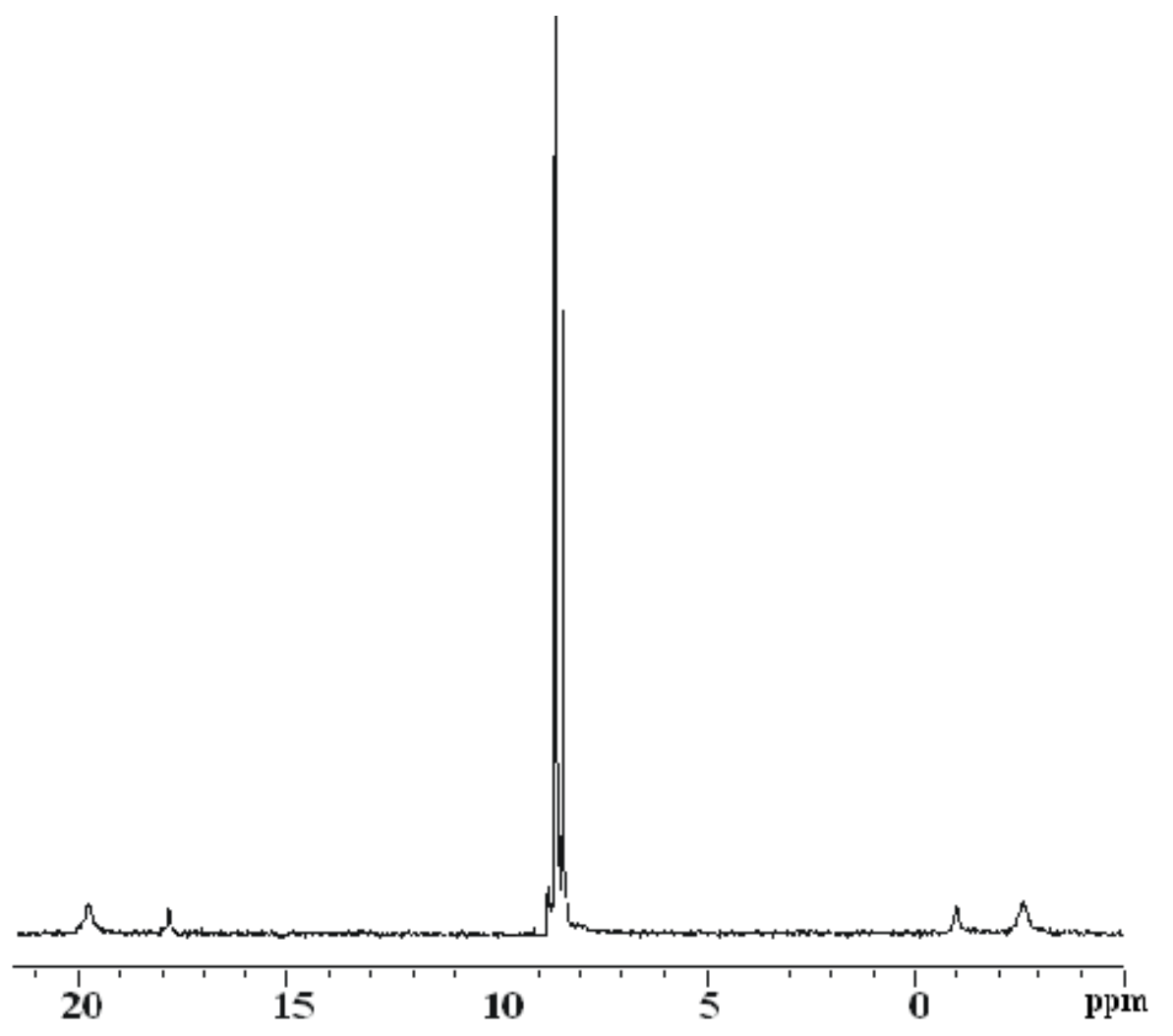

Figure-S2: ${ }^{31} \mathrm{P}$ NMR spectrum of complex-3. 